\title{
UMA NOVA ABORDAGEM PARA AS ENDOPRÓTESES PARCIAIS DE JOELHO EM SARCOMAS PRIMÁRIOS ÓSSEOS
}

\author{
A NEW APPROACH TO PARTIAL KNEE ENDOPROSTHESIS \\ IN PRIMARY BONE SARCOMAS
}

\author{
Valter Penna ${ }^{1}$, \\ Eduardo Areas Toller², \\ Carla Pinheiro ${ }^{3}$, \\ Ricardo Gehrke Becker ${ }^{4}$
}

\section{RESUMO}

Objetivo: As endopróteses parciais de joelho para as ressecções em sarcomas ósseos demonstram serem boa solução para o tratamento de pacientes com imaturidade esquelética. $\mathrm{O}$ objetivo deste estudo é avaliar o escore funcional, as vantagens, as desvantagens e indicações para esta técnica cirúrgica em quatorze pacientes em um protocolo brasileiro de osteossarcoma e sarcoma de Ewing. Métodos: Análise retrospectiva realizada para identificar a evolução funcional e as possíveis complicações do procedimento. 14 pacientes com idade entre 10 e 22 anos avaliados funcionalmente pelos critérios de Enneking/ISOLS (International Society of Limb Salvage), sendo todos operados na mesma Instituição e pelo mesmo cirurgião. Foram utilizadas endopróteses parciais das extremidades distal do fêmur e proximal da tíbia com reconstrução ligamentar. Resultados: A análise do escore funcional de Enneking/ISOLS demonstrou 78,6 \% de excelentes resultados e 21,4\% de bons. Dos 14 pacientes, todos portadores de tumores primitivos ósseos em protocolo de quimioterapia, nove não apresentaram nenhum tipo de complicação e cinco indivíduos evoluíram com complicações relacionadas ao procedimento, sendo que houve relação estatística positiva entre os maus resultados e a presença de complicações $(p=0,027)$. Conclusão: As endopróteses parciais de joelhos são menos prejudiciais ao estoque ósseo de pacientes com esqueleto imaturo. As críticas sobre os maus resultados funcionais estão sendo suplantadas pelas novas técnicas de reconstrução, corretos protocolos de reabilitação, qualidade e tecnologia dos implantes, e o aumento da curva de aprendizado. Essa opção de tratamento permite a preservação do estoque ósseo e a possibilidade de revisão da artroplastia não convencional de modo menos agressivo.

Descritores - Joelho; Sarcoma de Ewing; Osteossarcoma; Prótese do joelho; Estudos retrospectivos

\section{ABSTRACT}

Objective: Partial knee endoprosthesis to bone sarcomas resections seems to be a good solution to treat this immature skeletal patients. The purpose of this study is to evaluate the functional score in fourteen patients, advantages and the technique indications. Methods: Retrospective analysis was done to assess in this group of patients the functional evolution and the possible complications of the procedure. 14 patients between 10 and 22 years functionally evaluated in Ennekin/ISOLS (International Society of Limb Salvage) criteria, being all of them operated in the same institution by the same surgeon. Were used distal femur and proximal tibia partial endoprosthesis. Results: General analysis demonstrated that the functional results were over than 67 percent (ISOLS criteria) in 78,6 percent of the patients, being considered excellent. 21,4 percent were considered good results, being between 50 and 66 percent. Bone storage was preserved when avoiding the adjacent segment resection. Surgery time was not prolonged in ligament reconstruction. Conclusion: Knee partial endoprosthesis are less damage to bone storage in young patients. The critics about the bad functional results are being supplied by new surgical techniques, excellent rehabilitation protocols, implants technology and the consequent learning curve. This option of treatment permits the preservation of healthy bone and provides the possibility of a revision replacement less aggressive.

Keywords - Knee; Sarcoma Ewing's; Osteosarcoma; Knee prosthesis; Retrospective studies

1 - Médico Especialista em Oncologia Ortopédica; Chefe do Serviço de Oncologia Ortopédica do Hospital de Câncer de Barretos, SP.

2 - Médico Ortopedista Titular do Serviço de Oncologia Ortopédica do Hospital de Câncer de Barretos, SP.

3 - Médica Ortopedista Residente em Oncologia Ortopédica do Hospital de Câncer de Barretos, SP.

4 - Médico Ortopedista Residente em Oncologia Ortopédica do Hospital de Câncer de Barretos, SP.

Trabalho realizado no Hospital de Câncer de Barretos, SP - Departamento de Oncologia Ortopédica.

Correspondência: Rua Antenor Duarte Vilela, 1331 - Bairro Dr. Paulo Prata - CEP 14784-400 - Barretos, SP - Departamento de Ortopedia.

Email: ricardogbecker@hotmail.com / walter_penna@terra.com.br

Declaração: Não houve auxílio, de qualquer espécie, a esta pesquisa e não há conflitos de interesse dos autores em relação ao presente manuscrito, conforme Resolução $\mathrm{n}^{\circ} 1.595 / 2000$ do Conselho Federal de Medicina. 


\section{INTRODUÇÃO}

Os tumores ósseos primários malignos mais comuns na infância e da adolescência são o osteossarcoma e o sarcoma de Ewing. Apresentam como um dos principais sítios de localização a extremidade distal do fêmur e proximal da tíbia. Estas localizações comprometem muitas vezes a articulação do joelho, necessitando, de cirurgias preservadoras com a substituição dos segmentos por endopróteses. Diversos modelos de endopróteses estão disponíveis para as mais variadas indicações cirúrgicas nas ressecções de tumores ósseos do joe1 ho ${ }^{(1)}$. No entanto, em casos onde o tumor não respeita os limites da cartilagem de crescimento, invadindo a epífise dos ossos longos do joelho, sem invasão articular, é possível indicar a ressecção com substituição por endoprótese parcial. Esta técnica permite a ressecção em bloco da extremidade distal do fêmur ou proximal da tíbia, preserva a epífise adjacente articular e substitui apenas o segmento afetado pelo implante fixado no fêmur ou na tíbia.

A utilização de endopróteses parciais se restringe a pacientes portadores de tumores com as características descritas acima e com imaturidade esquelética na faixa etária entre 10 a 16 anos. Indivíduos com idade entre 17 e 22 anos também se beneficiam das endopróteses parciais devido à preservação do estoque ósseo e ao crescimento residual até próximo do limite etário de $22 \operatorname{anos}^{(2)}$. Pacientes muito jovens, que não iniciaram o segundo estirão de crescimento, submetidos à substituição por implantes no membro inferior, com o passar dos anos apresentarão discrepâncias incompatíveis com a funcionalidade da extremidade inferior. $\mathrm{Na}$ opinião dos autores, nesses casos é mais prudente a cirurgia radical (amputação). Já em indivíduos que completaram o crescimento, as vantagens de preservar a região epifisária são muito menores, sendo mais indicada a endoprótese total de joelho ${ }^{(3,4)}$.

As ressecções com margem oncológica para tumores ósseos primários da infância e adolescência em passado não muito distante eram sinônimo de amputação de membro. O desenvolvimento de novas técnicas cirúrgicas, melhores condições hospitalares, a introdução da quimioterapia neo-adjuvante com protocolos bem definidos, o aperfeiçoamento dos tipos de implantes cirúrgicos e a curva de aprendizado dos cirurgiões ortopedistas proporcionaram mais segurança e qualidade de vida aos portadores dessas enfermidades ${ }^{(3,5-9)}$.
O aumento da sobrevida livre de doença e cura em tumores como o sarcoma de Ewing e o osteossarcoma trouxe a preocupação da vida útil do implante utilizado ${ }^{(10)}$. Implantes como as endopróteses totais de joelho em pacientes jovens apresentam a desvantagem de necessitar de ressecção ou osteotomia femoral/tibial para fixação do implante no segmento adjacente, e por conseguinte, remover a região de crescimento meta-epifisária. Isso implica em discrepância de crescimento das extremidades inferiores, diminuição do estoque ósseo e complicações futuras para revisão do implante devido à cimentação e a ressecção de osso não acometido por tumor.

Com o objetivo de reduzir complicações como às descritas e avaliar a funcionalidade e características dos pacientes submetidos a esta indicação de exceção, analisamos os casos onde foram utilizados implantes parciais não articulados (endopróteses parciais) de joelho em pacientes jovens, associados a reconstrução ligamentar, nas ressecções com margem oncológica na extremidade distal do fêmur e proximal da tíbia.

\section{MÉTODO}

Todos os pacientes foram operados pelo grupo de oncologia ortopédica do Hospital de Câncer de Barretos, SP. Foram avaliados de modo retrospectivo 14 pacientes incluídos nos Protocolos Brasileiros de Osteossarcoma e Ewing, com idade entre 10 e 22 anos, submetidos a ressecção da extremidade distal do fêmur ou proximal da tíbia devido a tumores ósseos primários com substituição por endoprótese parcial de joelho não articulada e reconstrução ligamentar.

A indicação cirúrgica foi baseada em características morfológicas do tumor no joelho, ou seja, tumores localizados no fêmur distal ou tíbia proximal com invasão da cartilagem de crescimento e epífise, mas sem comprometimento articular visível à Ressonância Magnética. A presença de metástases pulmonares não foi critério de exclusão.

Todos os casos foram operados com critérios oncológicos no período entre fevereiro de 2003 e fevereiro de 2008 na mesma Instituição e pelo mesmo cirurgião. Os 14 pacientes apresentaram margens cirúrgicas livres no exame anátomo-patológico.

Os implantes de escolha foram: Endoprótese para extremidade distal do fêmur Parcial Não Articulada $\left(\right.$ Impol $\left.^{\circledR}\right)$ para tumores da extremidade distal do fêmur e Endoprótese de extremidade distal da tíbia Parcial Não Articulada $\left(\operatorname{Impol}{ }^{\circledR}\right)$ para as neoplasias da extre- 
midade proximal da tíbia. O implante é constituído de uma liga metálica de cromo-cobalto-molbidênio em sua superfície articular, reduzindo ao mínimo o atrito com a cartilagem normal do segmento adjacente. O corpo da endoprótese foi fabricado em polietileno de ultra alto peso molecular e a haste femoral ou tibial confeccionada em liga de titânio. A fixação do implante ao osso foi feita com cimento ósseo radiopaco.

A avaliação funcional foi baseada no escore como proposto por Enneking et al ${ }^{(11)}$. O escore é baseado em seis variáveis (dor, função, aceitação emocional, uso de sustentação como bengalas ou muletas, deambulação e marcha) sendo a cada uma atribuídos no máximo 5 pontos. O somatório total pode ser de até 30 pontos. O número de pontos do paciente é então dividido pelo valor máximo (30 pontos). Encontra-se, então, uma porcentagem que é expressa da seguinte forma: excelente $(67 \%$ $-100 \%)$, bom $(50 \%-66 \%)$ e ruim $(<50 \%)$ de acordo com um seguimento de no mínimo seis meses de pós-operatório. Todos pacientes foram orientados a permanecerem com um tutor no pós-operatório por período entre 60 a 90 dias sem carga e, após, foram incluídos, pelos autores, em protocolo de reabilitação para ganho de arco de movimento, propriocepção e reforço muscular ${ }^{(12,13)}$.

As variáveis quantitativas foram descritas por meio de média \pm desvio padrão e as variáveis qualitativas por freqüências absolutas e relativas.

Para avaliar possíveis associações entre as variáveis categóricas foi utilizado o teste exato de Fisher. Para comparar médias, foi utilizado o teste $t$ de student.

O nível de significância adotado foi de $5 \%(\mathrm{p} \leq 0,05)$ e as análises foram realizadas no programa SPSS (Statistical Package for the Social Sciences) versão 13.0.

Nos 14 pacientes avaliados, a média de idade foi de 13,5 $\pm 3,5$ anos. Quanto ao sexo, 10 dos pacientes $(71,4 \%)$ eram do sexo feminino e quatro $(28,6 \%)$ do masculino. Neste grupo, osteossarcoma aparecia em doze dos pacientes $(85,7 \%)$, enquanto um $(7,1 \%)$ pertencia ao grupo dos sarcomas de Ewing, e um $(7,1 \%)$ teve como diagnóstico fibrohistiocitoma maligno (protocolo de tratamento igual ao osteossarcoma). Nove dos tumores $(64,3 \%)$ se localizava na extremidade distal do fêmur cinco $(35,7 \%)$ na extremidade proximal da tíbia. A maioria dos pacientes $(57,1 \%)$ eram procedentes do Estado de São Paulo.

O estudo foi aprovado pelo Comitê de Ética em Pesquisa do Hospital de Câncer de Barretos - Fundação Pio XII.

\section{RESULTADOS}

A análise dos dados obtidos demonstrou que onze dos pacientes $(78,6 \%)$ obtiveram escore de Enneking excelente, e que três $(21,4 \%)$ apresentaram resultado bom. A presença de complicações foi baixa, todas resolvidas no pós-operatório recente. Dos 14 pacientes, nove não apresentaram qualquer complicação em relação à artroplastia; um apresentou infecção superficial; um apresentou instabilidade articular, com subluxação, provavelmente devido a retirada muito precoce da imobilização na cidade de origem; outros três evoluíram com complicações como: úlcera de pressão e ruptura do tendão patelar na prótese tibial. Dos pacientes com escore bom, 100\% apresentaram complicações pós-operatórias $(p=0,027)$, portanto as complicações no transcorrer do tratamento diminuíram a funcionalidade do joelho (Gráfico 1).

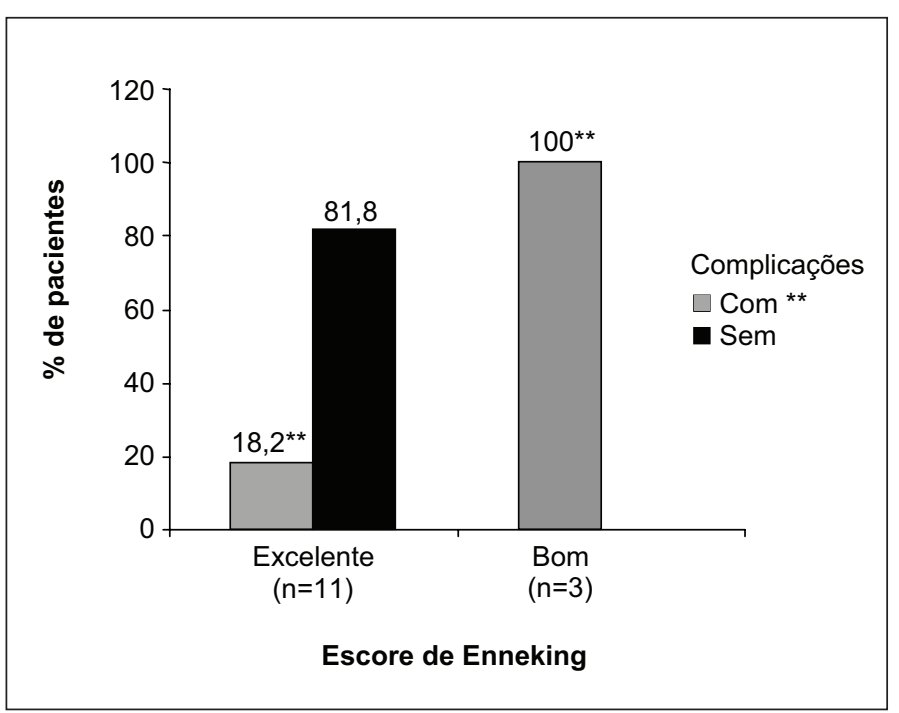

Gráfico 1 - Associação entre o escore de Enneking com a incidência de complicações $(p=0,027)$.

O tempo médio de imobilização foi de $9,76 \pm 3,3$ semanas (máximo 16,4 e mínimo 3,8 semanas) e o tempo médio de seguimento dos pacientes foi de $23,1 \pm 15,8$ meses (máximo 68,2 e mínimo 2,2 meses). Verificamos que o grupo com maior tempo de imobilização apresentou melhor escore funcional $(\mathrm{p}=0,048)$ (Gráfico 2).

Não identificamos correlação estatística entre a idade dos pacientes e o escore funcional. Os indivíduos mais jovens não obtiveram melhor funcionalidade do joelho.

A localização do tumor ou na extremidade proximal da tíbia ou distal do fêmur não foi responsável por variação no escore de Enneking com significância estatística. 


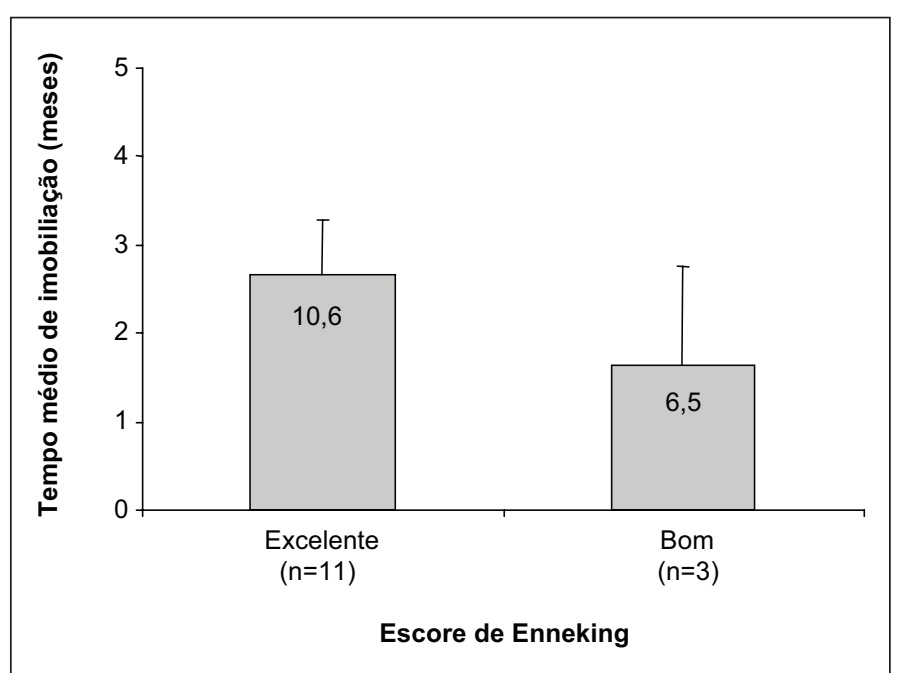

Gráfico 2 - Avaliação do tempo médio de imobilização conforme o escore de Enneking ( $p=0,048)$.

No seguimento dos pacientes, identificamos onze $(78,6 \%)$ que estão vivos e três $(21,4 \%)$ que foram a óbito devido à progressão da doença (Tabela 1).

Tabela 1 - Caracterização da amostra.

\begin{tabular}{|c|c|}
\hline Variáveis & $n=14$ \\
\hline Idade (anos) - Média \pm DP & $13,5 \pm 3,6$ \\
\hline \multicolumn{2}{|l|}{ Sexo - n(\%) } \\
\hline Masculino & $4(28,6)$ \\
\hline Feminino & $10(71,4)$ \\
\hline \multicolumn{2}{|l|}{ Tipo de tumor - n(\%) } \\
\hline Osteossarcoma & $12(85,7)$ \\
\hline S. Ewing & $1(7,1)$ \\
\hline FHM & $1(7,1)$ \\
\hline \multicolumn{2}{|l|}{ Local do tumor - n(\%) } \\
\hline Fêmur & $9(64,3)$ \\
\hline Tíbia proximal & $5(35,7)$ \\
\hline \multicolumn{2}{|l|}{ Escore de Enneking/ISOLS - n(\%) } \\
\hline Excelente & $11(78,6)$ \\
\hline Bom & $3(21,4)$ \\
\hline \multicolumn{2}{|l|}{ Complicações - n(\%) } \\
\hline Sem complicações & $9(64,3)$ \\
\hline Infecção & $1(7,1)$ \\
\hline Instabilidade & $1(7,1)$ \\
\hline Outras & $3(21,4)$ \\
\hline $\begin{array}{l}\text { Tempo de imobilização (semanas) } \\
\text { - Média } \pm \text { DP }\end{array}$ & $9,76 \pm 3,3$ \\
\hline $\begin{array}{l}\text { Tempo de seguimento (meses) } \\
\text { - Média } \pm \text { DP }\end{array}$ & $23,1 \pm 15,8$ \\
\hline \multicolumn{2}{|l|}{ Estado Atual - n(\%) } \\
\hline Vivo & $11(78,6)$ \\
\hline Óbito & $3(21,4)$ \\
\hline
\end{tabular}

\section{DISCUSSÃO}

A introdução da quimioterapia neoadjuvante nos anos 80 aumentou muito a possibilidade de ressecção tumoral com preservação de membro. Mais de $80 \%$ dos pacientes com osteossarcoma de extremidade se tornaram candidatos a cirurgia preservadora de membro ${ }^{(3)}$. A cirurgia preservadora para tumores ósseos primários muito volumosos necessita de grandes ressecções no nível do joelho e criam defeitos segmentares importantes que necessitam de algum tipo de substituição que conserve a funcionalidade articular (Figuras 1 e 2). Os métodos de substituição podem ser os mais variados, entre eles estão alternativas biológicas, como o uso de enxerto livre ou vascularizado do próprio paciente ou de outros indivíduos (aloenxerto). Outras opções incluem as endopróteses distais do fêmur e proximais da tíbia. Entre as diferentes endopróteses comercializadas podemos descrever as articuladas fixas, rotatórias e as do tipo artrodese. Algumas utilizam cimento para a fixação femoral e outras são fixadas pelo método press- $\mathrm{fit}^{(4)}$.
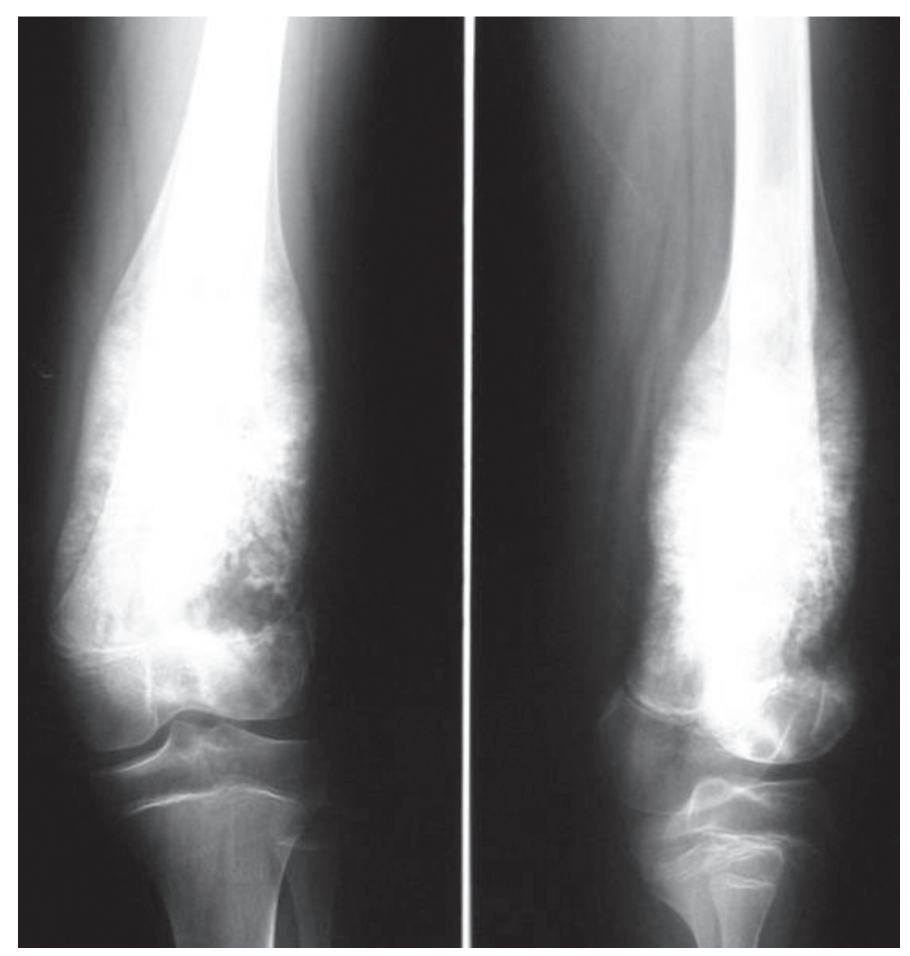

Figura 1 - Raio $X$ do joelho

A indicação cirúrgica para tumores localizados na extremidade distal do fêmur e proximal da tíbia depende da relação anatômica da neoplasia com as estruturas que fazem parte do joelho normal. Tumores que invadem a articulação do joelho tornam o paciente candidato ressecção extra-articular com ou sem artrodese, e 


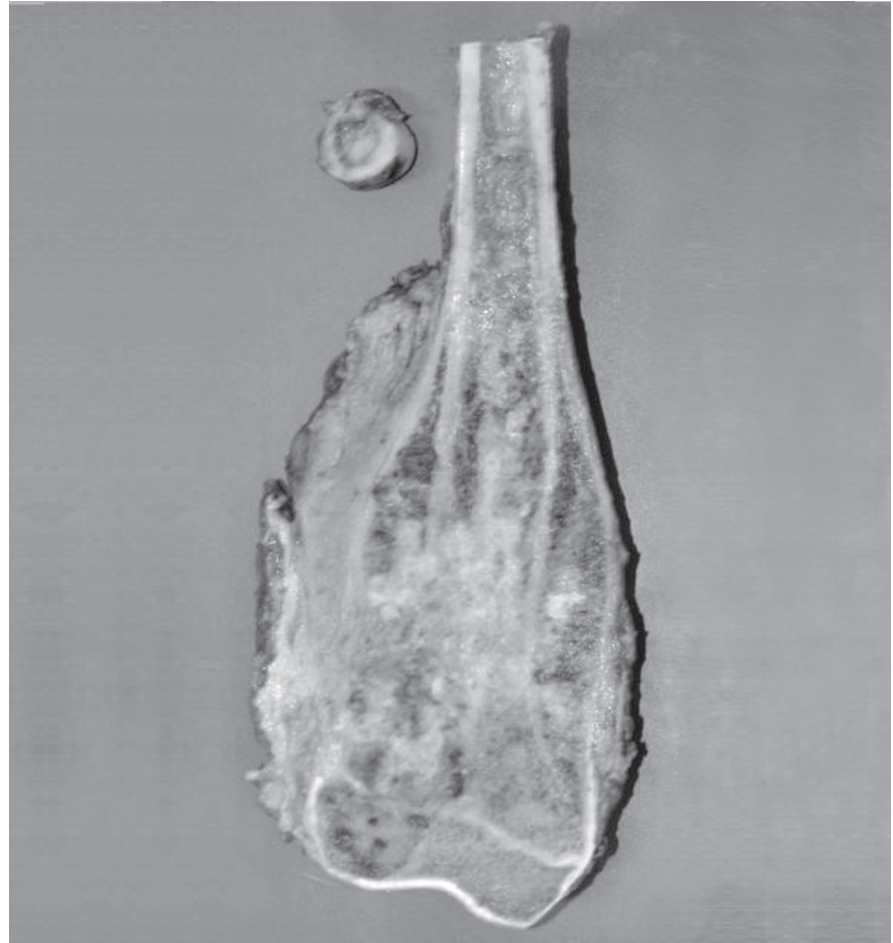

Figura 2 - Corte de peça

conseqüentemente, restrição funcional parcial ou total. As neoplasias que não invadem a articulação, mas que comprometem a cartilagem de crescimento e a epífise, limitam as alternativas cirúrgicas e obrigam o cirurgião ortopedista a lançar mão de certos procedimentos mais específicos. Entre eles, o aloenxerto osteoarticular foi descrito como boa alternativa em trabalho realizado por Muscolo et al ${ }^{(14)}$ com 80 pacientes portadores de tumores na extremidade distal do fêmur submetidos a esse método e com seguimento de cinco a 10 anos. Essa alternativa, no entanto, é descrita por muitos autores apresentando complicações como fratura do enxerto, pseudoartrose, infecção, osteoartose secundária a osteonecrose condilar ${ }^{(15-17)}$

Uma alternativa que é usada há muito tempo para tumores localizados no joelho de jovens são as endopróteses totais articuladas para extremidade distal do fêmur e proximal da tíbia. Este implante fornece estabilidade, retorno mais rápido às atividades e melhor qualidade de vida ao portador de tumores ósseos. No entanto, em pacientes esqueleticamente imaturos seu uso compromete a epífise do osso adjacente, resultando em diminuição do estoque ósseo e piora da discrepância entre os membros inferiores. A indicação deste tipo de implante se encaixa melhor em indivíduos que não apresentam mais cartilagem de crescimento aberta ou que já estejam encerrando, pelo menos, o segundo estirão de crescimento ${ }^{(2-4,18)}$.
Optamos nesse estudo por um implante que substituiu apenas a extremidade distal do fêmur ou a extremidade proximal da tíbia (Figuras 3, 4 e 5). Todos pacientes apresentavam invasão tumoral da cartilagem de crescimento, mas sem penetrar na cavidade articular ou extensão para ligamentos cruzados. O implante permitiu a preservação da epífise do osso adjacente (tíbia ou fêmur), reduzindo o risco de discrepância e problemas futuros com o pouco estoque ósseo nas revisões da prótese. Foi necessária a reconstrução ligamentar

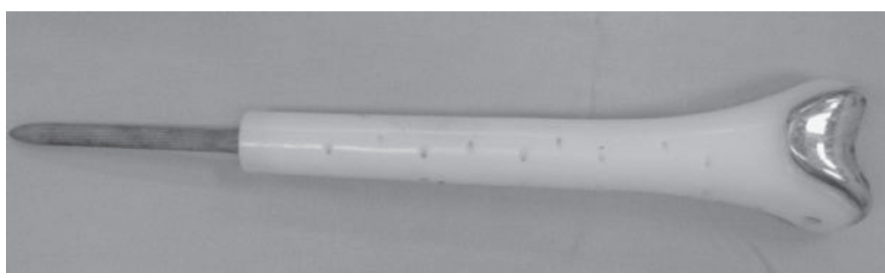

Figura 3 - Endoprótese não convencional tipo Fabroni

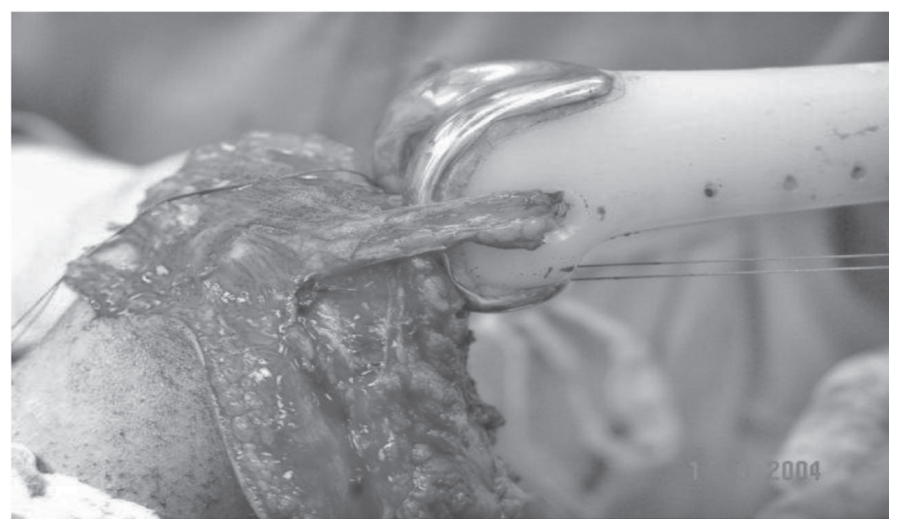

Figura 4 - Reconstrução articular

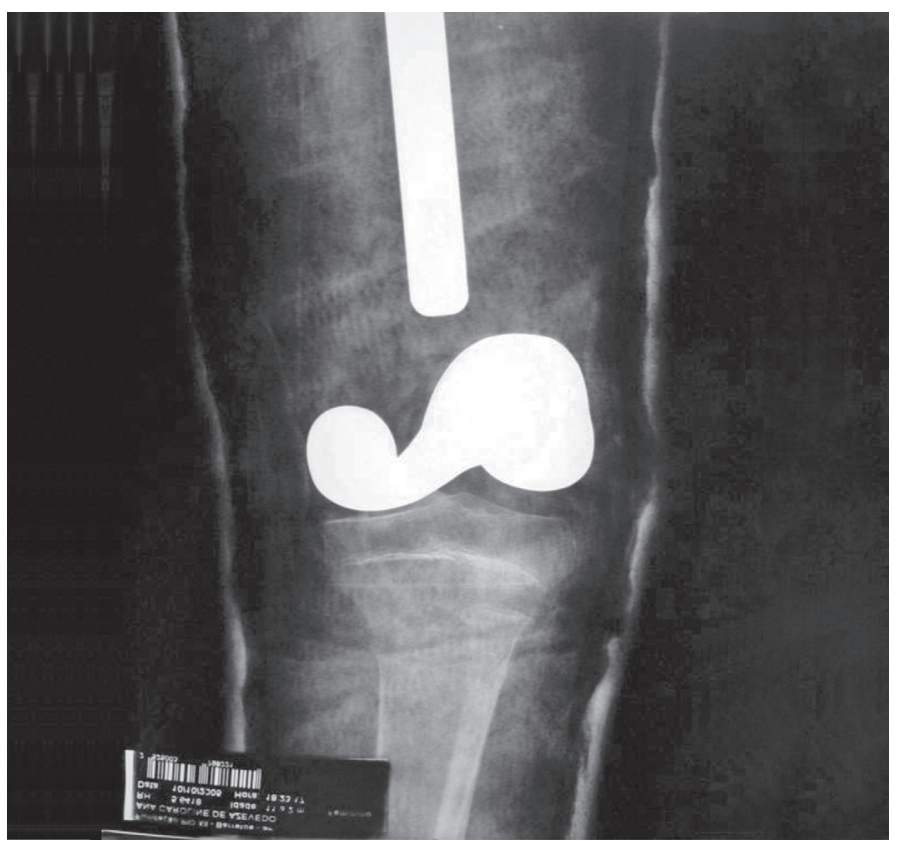

Figura 5 - Raio X controle 
dos cruzados e colaterais; além do tendão patelar nas substituições da extremidade proximal da tíbia. Apesar da necessidade de reconstrução dos ligamentos, o tempo cirúrgico permaneceu muito semelhante ao das endopróteses totais de joelho, pois não se perdeu tempo com osteotomia do segmento adjacente.

Não há artigos que descrevam este implante parcial sendo avaliado isolado das endopróteses totais de joelho. O método apresenta uma série de vantagens em relação aos implantes articulados em pacientes com imaturidade esquelética. Clinicamente, a avaliação dinâmica da marcha se assemelha muito às artroplastias não convencionais totais ${ }^{(19,20)}$. Apesar de haver certo grau de hiperlaxidão estática, não há instabilidade durante o ortostatismo ou deambulação. A ação muscular nas fases de apoio e balanço mantém o joelho estável. Esse estudo

\section{REFERÊNCIAS}

1. Kawai A, Muschler GF, Lane JM, Otis JC, Healey JH. Prosthetic knee replacement after resection of a malignant tumor of the distal part of the femur: medium to long-term results. J Bone Joint Surg Am. 1998;80(5):636-47.

2. Behrman K, Jenson. N. Tratado de pediatria. $17^{\circ}$ ed. Rio de Janeiro: Elsevier; 2005.

3. Futani H, Minamizaki T, Nishimoto Y, Abe S, Yabe H, Ueda T. Long term follow-up after limb salvage in skeletally immature children with a primary malignant tumor of the distal end of the femur. J Bone Joint Surg. 2006;88(3):595-603.

4. Krepler $P$, Dominkus $M$, Toma CD, Kotz R. Endoprosthesis management of the extremities of children after resection of primary malignant bone tumors. Orthopade. 2003;32(11):1013-9.

5. Almeida MTA. Tratamento combinado do Sarcoma de Ewing: análise do Protocolo Ewing -II -94 [tese]. São Paulo: Faculdade de Medicina da Universidade de São Paulo; 2000.

6. Croci AT, Camargo OP, Oliveira NRB. Tratamento cirúrgico do sarcoma de Ewing: avaliação oncológica funcional. Rev Bras Ortop. 1996;31(11):909-18.

7. Penna V, Lopes A, Tanaka MH, Wu TC, Melaragno R, Epelman S. Osteossarcoma: tratamento multidisciplinar. Rev Bras Ortop. 1993;28(11/12):791-4.

8. Petrilli AS, Macedo CRD. Tumores ósseos malignos na criança e no adolescente. Pediatria Moderna.1999; 35:600-8.

9. Próspero JD. Tumores ósseos. São Paulo: Roca; 2001.

10. Rougraff BT, Simon MA, Kneisl JS, Greenberg DB, Mankin HJ. Limb salvage compared with amputation for osteosarcoma of the distal end of the femur. A long-term oncological, functional, and quality-of-life study. J Bone Joint Surg Am.1994; 76(5):649-56.

11. Enneking WF, Dunham W, Gebhardt MC, Malawar M, Pritchard DJ. A system for the functional evaluation of reconstructive procedures de 14 pacientes demonstra excelentes resultados na avaliação funcional, sendo que os indivíduos que evoluíram com alguma complicação acabaram apresentando escore inferior. A análise biomecânica na marcha in vivo de endopróteses parciais necessita ainda investigação mais aprimorada, sendo esse estudo realizado no Hospital de Câncer de Barretos um dos primeiros passos para a afirmação dessa técnica cirúrgica.

\section{CONCLUSÃO}

As endopróteses parciais de joelho proporcionam ao ortopedista e ao paciente um método preservador da extremidade com excelente funcionalidade, manutenção do estoque ósseo para revisão, e redução de discrepâncias em indivíduos esqueleticamente imaturos.

after urgical treatment of tumors of the musculoskeletal system. Clin Orthop Relat Res. 1993;(286):241-6.

12. Schultz K, Souza RV. Fisioterapia. Kowalski LP. Manual de condutas diagnósticas e terapêuticas em oncologia. $2^{\mathrm{a}}$. ed. São Paulo: Âmbito; 2002.

13. Tsai LY, Jesus-Garcia Filho R, Petrilli AS, Korukian M, Viola DCM, Petrilli $\mathrm{M}$, et al. Protocolo fisioterapêutico em pacientes submetidos à endoprótese não convencional de joelho por osteossarcoma: estudo prospectivo. Rev Bras Ortop. 2007;42(3):64-70.

14. Muscolo DL, Ayerza MA, Aponte-Tinao LA, Ranalletta M. Use of distal femoral osteoarticular allografts in limb salvage surgery. Surgical technique. J Bone Joint Surg Am. 2006;88(Suppl 1 Pt 2):305-21

15. Harrington KD, Johnston JO, Kaufer HN, Luck JV Jr, Moore TM. Limb salvage and prosthetic joint reconstruction for low-grade and selected high-grade sarcomas of bone after wide resection and replacement by autoclaved autogenic grafts. Clin Orthop Relat Res. 1986;(211):180-214.

16. NishidaJ, Shimamura T. Methods of reconstruction for bone defect after a tumor excision: a review of alternatives. Med Sci Monit. 2008;14(8):RA107-13.

17. Komiya K, Nasuno S, Uchiyama K, Takahira N, Kobayashi N, Minehara $\mathrm{H}$, et al. Status of Bone Allografting in Japan - NationWide Survey of Bone Grafting Performed from 1995 through 1999. Cell Tissue Bank. 2003;4(2-4):217-20.

18. Roberts P, Chan D, Grimer RJ, Sneathe RS, Scales JT. Prosthetic replacement of the distal femur for primary bone tumors. J Bone Joint Surg Br. 1991;73(5):762-9.

19. Kabo JM, Yang RS, Dorey FJ, Eckardt JJ. In vivo rotational stability of the kinematics rotating hinge knee prosthesis. Clin Orthop Relat Res 1997;(336):166-76.

20. Dennis DA, Komistek RD, Scuderi GR, Zingde S. Factors affecting flexion after total knee arthroplasty. Clin Orthop Relat Res. 2007;(464):53-60. 